\title{
Research on modeling method for small agriculture machine based on
}

\author{
the ontology \\ Yun Luan ${ }^{1 a}$ Wei Liu ${ }^{2,3 b}$ Xiaoting Hou ${ }^{2,3 c}$ Guozhong Cao ${ }^{2,3 d *}$ \\ 1. The Administrative center for china's agenda21, Beijing 100038; \\ 2. School of Mechanical Engineering, Hebei University of Technology, Tianjin 300130; \\ ${ }^{3}$. National technological Innovation Method and Tool Engineering Research Center, Tianjin 300130 \\ a luany@acca21.org.cn, ${ }^{b}$ Iwofhebut@126.com, c270676360@qq.com, \\ d caoguozhong@hebut.edu.cn
}

Keywords: Small agricultural machinery; Knowledge modeling; Ontology; Harvest machinery

Abstract: Aiming at the development request of miniature farm machinery in our country, to improve the efficiency of the concept of small agricultural machinery design, put forward a kind of small agricultural machinery modeling method based on ontology, the modeling method and form a complete set of symbol system and modeling strategy, and put forward from the functional behavior - structure - tools the four aspects of modeling and design knowledge representation method, in order to improve the small farm machinery in the concept design to product design domain knowledge reuse, and finally, to a multi-purpose small crop harvest of agricultural machinery design knowledge modeling, for example, to verify the practicability and validity of this method .

\section{Introduction}

Agricultural mechanization is an important symbol of modernization [1]. It is of great significance in the process of social modernization. Agricultural machinery is an important tool for agricultural production, it is of great significance for realizing the modernization of agriculture.The development of small agricultural machinery is more suitable for our country because the special national conditions and he difference of natural geographical environment [2]. Small agricultural machinery (SAM) refers to that miniature farm machinery with small volume and light weight and independent power source [3]. The key to design of small agricultural machinery is how to use the existed design knowledge or technical resources effectively to improve the efficiency.

Researchers have got a series of achievements that has reference valuecentering on the design method research of small agricultural machinery. Zhen[4] proposed a kind of combined harvesting machine with functions of furrow tillage and sow. This is a small multi-function of agricultural machinery, it can finish all the farming operations such as plugging, fertilization, seeding, and coating the soil with film. Our country's agricultural mechanization research academy has developed a kind of integratedcombined operation machinery, it can provide different series of machineries through different combination to meet different demands of customers. Jia and Chen [5] the natural conditions in the north in China, have discussedthe plowing joint operation process method, optimized and combined productive agricultural technologyaccording to the characteristics of the agricultural work in North China. Zhang[6]has proposed a design method of system of reconfigurable modularization for agricultural machinery products and proposed reconfigurable principle, it can combined with a variety of design methods to develop a new modular design system, 
and this new type of modular design method can be applied to multiple links of agricultural machinery design, so it can realize the application of agricultural functional design stage, and even the detailed design stage.

The implementation of small agricultural machinery reconfigurable design depends on effective use of design knowledge about its ownfields. So this paper proposes a knowledge modeling method based on the ontology, this method can support conceptual design for SAM, andintegrate design knowledge of different stage in conceptual design.it can give effective knowledge tool support for reconfigurable design of small agricultural machinery to response market demand quickly.

\section{SAM function modeling based on ontology}

The basic concept of ontology and its application in product conceptual design

Ontology is firstly put forward by the 17 th-century German scholastics Guo Kelan, it can make objective descriptions for the real existence in any areas in the world[7-8]. McCary[9] first found the relationship between ontology and logical build activities of artificial intelligence, then more and more AI scholars applying ontology in the field of information science. The principle and method of ontology can be used. Liu Kang [10]applied ontology general principles tofunctional modeling ofmechanical products.As to mechanical products, they use ontology for theirfunction modeling- mainly use the relevant knowledge in the ontology, establish mutual relationship between all objects, functions andstructure of the organization related to the product function design. Wang [11] put forward the principle of ontology and component reuse from the perspective of software reuse; he pointed out that in the process of computer software product design. $\mathrm{Li}$ [12] put forward product information organization and method of system realization system based on ontology, and a method of building product ontology, which is used to describe information about product design environment.

Therefore we put forward a small agricultural machinery designoriented knowledge modeling method kind of based on ontology, it can establish mutual relationships betweendesign knowledge in different levels based on ontology, and provide knowledge security for reconfigurable design andrapid response design for small agricultural machinery.

SAM functionmodeling theory and symbolic system based on ontology

Functional design of product is one of the key tasks of product conceptual design, it mainly analyze the overall functional requirementsof product design according to users'demand. The production functional description has concepts both in the level of definition and the level of technical. Product functional modeling is the process of expressing the key information of the product function through visual symbols.

Every kind of product modeling method has a supporting a set of symbol system. The complete product function modelcontains three important elements: entities, relationships and characteristics. Entity category: entity can be divided into three kinds: source of action, function and flow; relationship categories: relationship can be divided into two kinds: one issubordinate relationship, the other is mutual relationship; Attributes can be divided into two kinds, one kind is subordinate attributes, the other is inherited attributes.

Each specific category has its corresponding specific symbol. The resulting symbol system is shown in Table 1. 
Table 1Mechanical products' co-modeling symbol system based on ontology

\begin{tabular}{|c|c|c|c|}
\hline Name & Category & symbol & meaning \\
\hline source of action & entity & $\mathrm{S}$ & $\begin{array}{l}\text { source of action of } \\
\text { function }\end{array}$ \\
\hline object of action & entity & $\mathrm{O}$ & $\begin{array}{l}\text { object of action of } \\
\text { function }\end{array}$ \\
\hline flow & entity & $\mathrm{F}$ & carrier of function \\
\hline $\begin{array}{l}\text { subordinate } \\
\text { relationship }\end{array}$ & relationship & domain & $\begin{array}{l}\text { attributes subjected to } \\
\text { entity objects }\end{array}$ \\
\hline mutual relationship & relationship & range & $\begin{array}{l}\text { attributes acting on } \\
\text { entity objects }\end{array}$ \\
\hline subordinate attributes & attributes & & $\begin{array}{l}\text { characteristics of the } \\
\text { entity itselfworksInside } \\
\text { the system }\end{array}$ \\
\hline inherited attributes & attributes & & $\begin{array}{l}\text { the inheritance of entity } \\
\text { characteristicsworks } \\
\text { outside the system }\end{array}$ \\
\hline
\end{tabular}

SAM function modeling strategy and process based on ontology

Small agricultural machinery function modeling processbased on ontology need to follow these four strategies:

(1).The strategy of functional elements transformation:

The first problem to solve is transferring the product functional elements into entity elements in symbol system.

(2).The strategy of function carrier

Analyze carrier information of each functional element then form different distribution sub-gram focused to each functional element to achieve different entities - properties.

(3). The strategy of analyzing the relationship of each functional elements

Analyze the relationship between each functional elements and guide the subordinate relationship or mutual relationship between each functional elements, this job is similar to the process of traditionally establish of the product function structure.

(4). The strategy to judge integrity of function modeling:

Verifying integrity in the correspondence of attributes and entities and integrity in the correspondence of attributes-entitiesrelationship.

Specific modeling process according to the above mentionedmodeling strategy is shown in figure 1. Specific steps contains seven steps:

Step 1: Analyze and determine the total function of product.

Step 2: Decompose the total function of product to obtain each functional elements of product .

Step 3: Transfer the functional elements of product into entity category.

Step 4: Class the entity category analyzed.

Step 5: Ascertain all kinds of attributes of eachentity category.

Step 6: Analyzeand ascertain the relationship between each entity and functional elements .

Step 7:Verify the integrity of the model and complete the modeling work. 


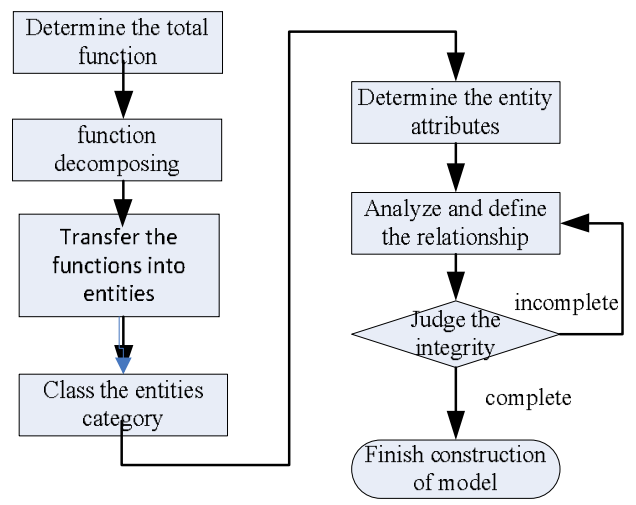

Fig1.Small agricultural machinery function modeling flowchart based on ontology

\section{Ontology and SAM design knowledge modeling based on function - behavior - structure - tool mapping}

Classification principle of SAM functional module based on ontology.

SAM is a special mechanical product, it has complete energy conversion link or walking mechanism (active or passive), and so from the point of view of dividing mechanical products' functional module, agricultural machinery, especially the SAM is a complete mechanical system. This system contains: actuator module, energy or power modules, power transmission module, signal transmission and control module, running gear module, man-machine interface module-totally seven function modules.

When we use ontology to establish functional modeling SAM, the key elements in the process of modeling mainly includes three types: independent system module, interface module and function relationship. Function is a property relationship of module in level of system model. If we distinguish function from their roles in system module, it can be viewed as a subordinate or related attributes in system module. The relationship between the function and the system module can be divided into single source relationship and double output function relationship for function of interface module, single source and single output relationship for function of individual modules in the system. Self sealed functional chains exists in independent modules system function, different independent modules establish a connection through the interface module. The model form is shown in Fig 2.

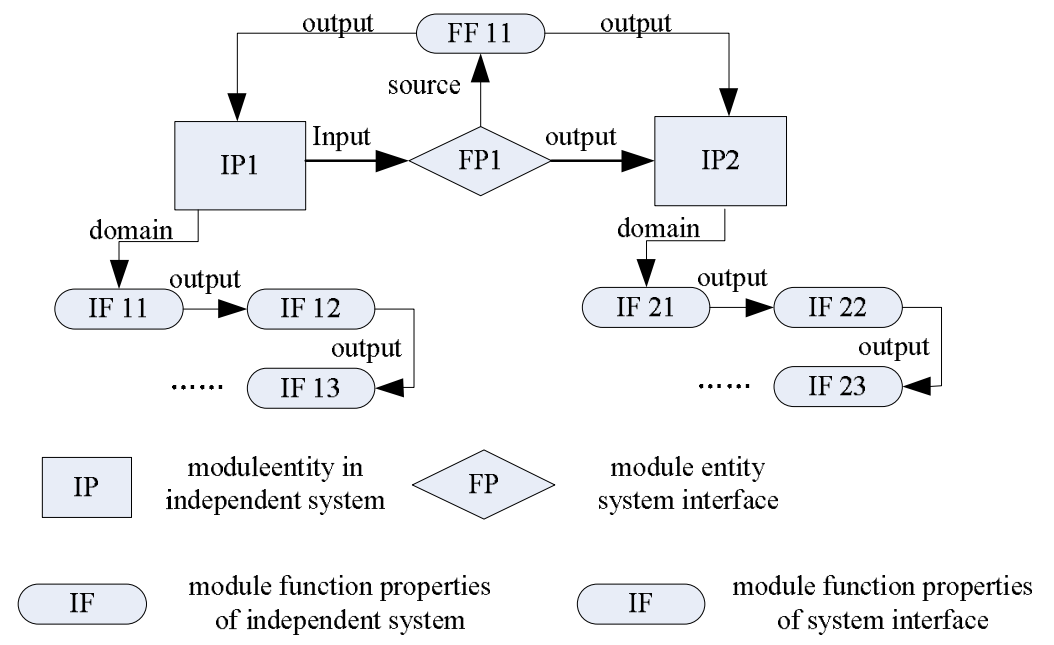

Fig2. The product function module model based on ontology

F - B - S - T mapping process oriented SAM design knowledge modeling.

According to the modeling method based on ontology, the above mentioned two modeling 
strategy give methods or strategies for modeling product knowledge based on ontologyrespectively from the level of analysis and the establishment of product functional structure and the level of constitution of product technology system' functional modules. Design knowledge standardized by ontology method is not just the one-to-one mapping relationship of functional or principle level, it involves the process of knowledge reuse related to design knowledge principles, functions, structure and the process of reuse and components between multi-level related process.

Product conceptual design is the process of transforming product functional requirements into corresponding available technology principle, the most ideal result is to find technical structure elements to realize product functional requirements, this process is called a function - behavior - structure mapping ( F - B -S), a more ideal result is the process of function - behavior - structure - tools ( $\mathrm{F}-\mathrm{B}-\mathrm{S}-\mathrm{T})$ mapping.

\section{Case studies}

We use the example of a new kind of SAM to verify the practicability and validity of the proposed method above.

Function analysis of a small potato harvesting device

We query relevant patent with the keyword potato (potato or sweet potatoes) to obtain the corresponding farm machinery equipment of patent documents, we obtain a typical small passive towed harvesting equipment technical plan, which is shown in figure3.

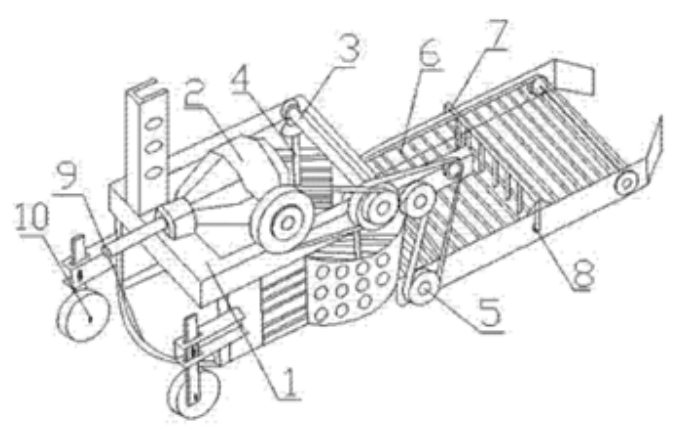

1.rack, 2. differential, 3. transfer bar, 4. soil breaking tools, 5. transport shaft, 6. conveying belt, 7. portable fence, 8.fixed metal column, 9. soil opener, 10.wheel

Fig3.Technology solutions of a small kind of potato harvesting device

Potato harvesting device, especially small passive towed potato harvesting device act as an important reference of target product design, an typical product in the field of target product design for later analysisofits function structure, technical system module and technical scheme, as well as the main reference of target products of reconfigurable design.If we use function modeling methods based on ontology to establish the function structure of the typical product, then use modeling methods of the existing traditional product functional structure, we can establish a typical product's functional decomposition results, which is shown in figure 6 , according to the relationship of each functional elements in figure 4 we establish the product function structure, which is shown in figure5. 


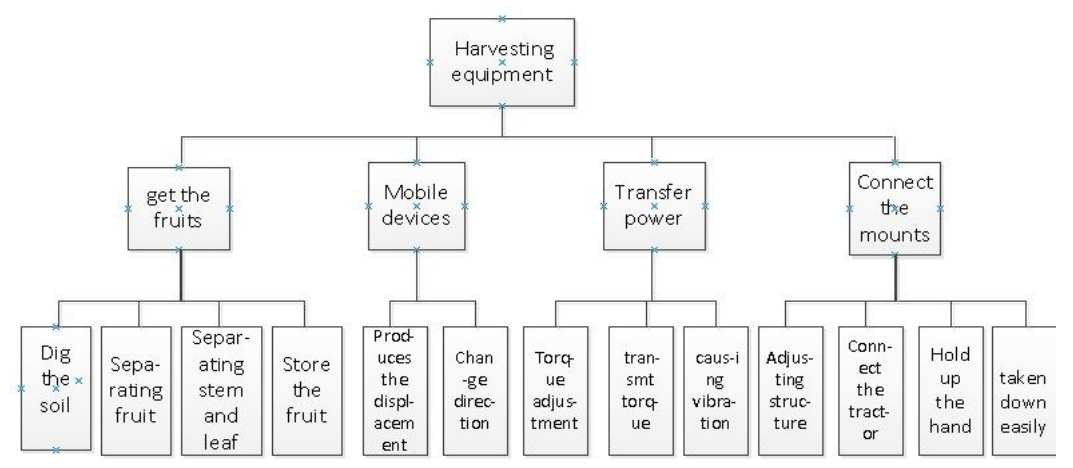

Fig 4. Functional decomposition diagram of small potato harvesting device

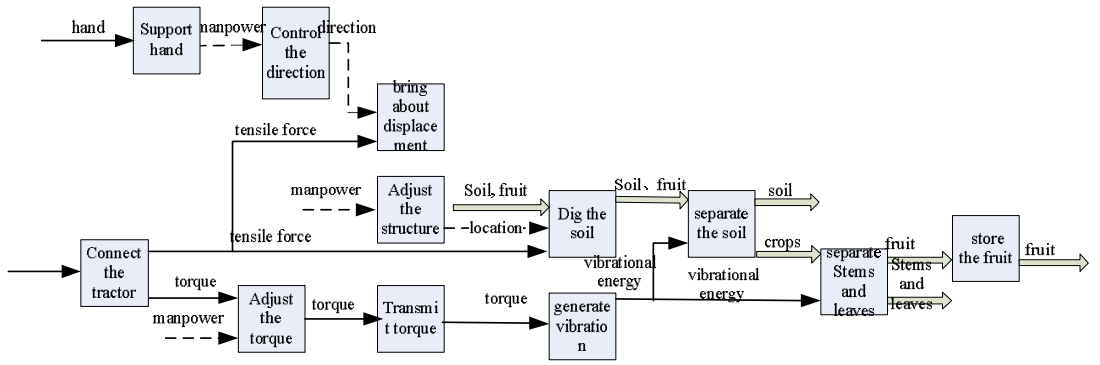

Fig5. Function architecture of small potato harvesting device

Design of new product based on design knowledge reuse

We can refer to the design knowledge model of small potato harvesting device and its reuse process of design knowledge to obtain a new small agricultural machinery products-a small passive multi-purpose harvest device, the design knowledge model is shown in figure 6 . The device is shown in figure 7. It can be connected with hand tractor, and the hand tractor can provide power for it. This device can be used in natural conditions such as hills, mountains and plains for harvest of agricultural crops shallow buried the surface such as peanuts, spring onion, taro and garlic.

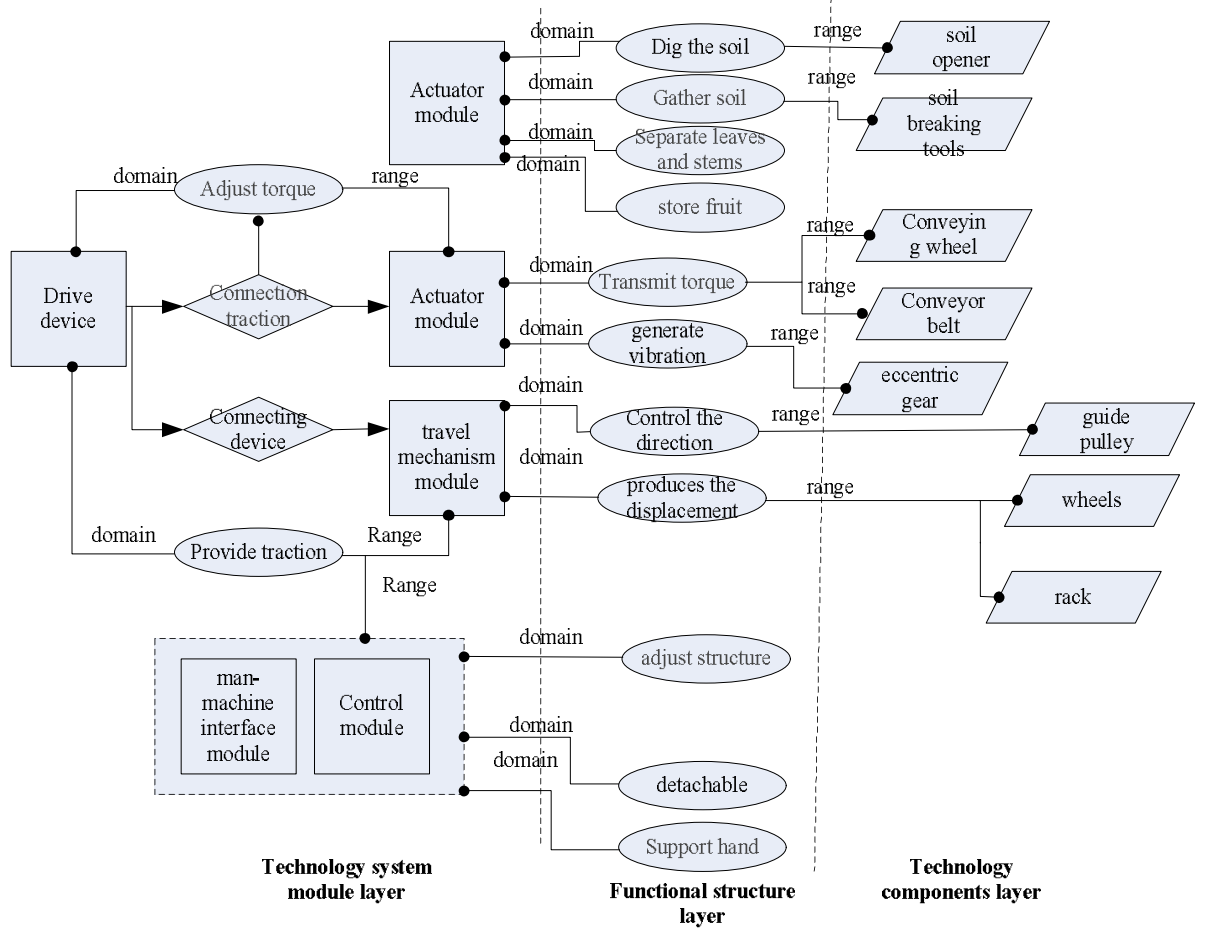

Fig 6. Design knowledge model for the target product based on ontology 


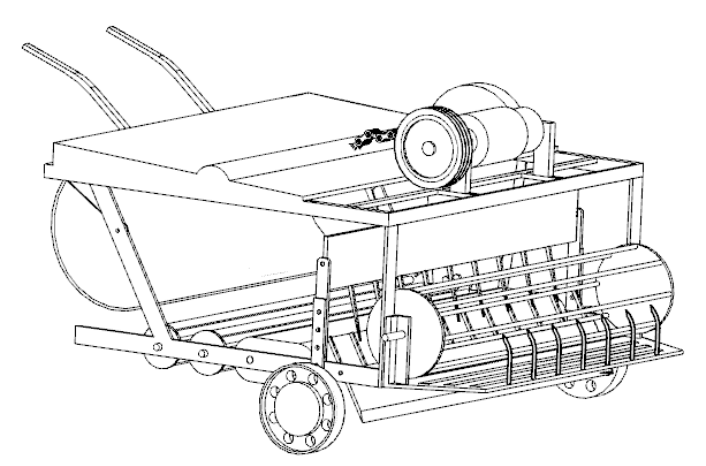

Fig 7. Structure for the new designed device

\section{Conclusions}

This article mainly studied and analyzed the feasibility of reuse of design knowledge, information, resources and process in small agricultural machinery's design process, in the process of feasibility study. For purpose of research, to achieve the goal, we firstly studied the description tools of SAM design knowledge standardization. This paper introduced the general ideas of ontology method, and proposed the product function structure modeling method based on ontology, and make it the basic analysis tool design knowledge standardization. Then studied the standardization of the design process, and proposed small agricultural machinery system module partition technology, design constraints conversion technology, reuse technology in process of design knowledge, formed modeling and application method system of agricultural machinery products' design knowledge, information, process based on the principle of ontology. This can guide the design work of practical small agricultural machinery equipment.

\section{Reference}

[1] FengQigao,MaoHanping. The development present situation and countermeasure on agricultural mechanization in China, J.Institute of Agricultural Engineering. 02 (2010):245-248.

[2] TU Zhi-qiang, YANG Min-li. Development Trends on Agricultural Mechanization in China,J.Chinese agricultural mechanization. 05(2005):3-7.

[3] XuQiong.Promotion Model of Urban Household Micro - Farming.Journal of Chinese Urban Forestry. 03(2013):53-56.

[4] ZHEN Zi-jian. Japan science and technology plan system and its organization and management mechanism, J .Global Science, Technology and Economy Outlook. 06 (2014) : 45-51.

[5] JiaHonglei,ZhaoJiale,etc. Design and experiment of anti-blocking mechanism for inter-row no-tillage seeder, J. Transactions of the Chinese Society of Agricultural Engineering. 18 (2013):16-25.

[6] Zhang Libin.Small agricultural machinery products reconfigurable modular design method and application. Science Press, Beijing. 2007.

[7]. T R Gruber.ONTOL INGUA: A mechanism to support portable ontologies. Stanford University, Tech Rep: KSL-91-66 . 1992.

[8] HaoYongping, Wang Chonghai.Study on knowledge sharing in the whole process of product based on ontology, J. Chinese Journal of Mechanical Engineering, 12 (2002):126-130.

[9] Xie Weiying,ZhangLiying. Several basic questions about study of ontology,J. Journal of Shanxi Normal University.05(2009):1-4. 
[10] LIU Kang, WANG Yu-ming, etc. Applying ontological theory for functional modelingof mechanical products,J.Chinese Journal of Construction Machinery. 04 (2007) :476-480.

[13] WANG Liangbin,ZHUGuojin.Meta Model of Web Resource Based on Ontological Mutual Attribute,J.Computer Engineering, 21(2004):81-82+182.

[14] LI Feng-lin,etc.Ontology-based Product Information Organization andSystem Implementation[J].Information Science.06(2009):889-893. 